\title{
E-Health literacy of medical and health sciences university students in Mashhad, Iran in 2016: a pilot study
}

\author{
Sareh Dashti ${ }^{1,2}$, Nooshin Peyman ${ }^{3}$, Mohammad Tajfard $^{3}$, Habibollah Esmaeeli $^{4}$
}

${ }^{1}$ M.Sc. Student of Health Education and Health Promotion, Department of Health Education and Health Promotion, School of Health, Social Determinants of Health Research Center, Mashhad University of Medical Sciences, Mashhad, Iran

${ }^{2}$ Department of Community Health, Faculty of Medicine and Health Sciences, Universiti Putra Malaysia (UPM), Serdang, Malaysia

${ }^{3}$ Ph.D., Associate Professor, Department of Health Education and Health Promotion, School of Health, Social Determinants of Health Research Center, Mashhad University of Medical Sciences, Mashhad, Iran

${ }^{4}$ Ph.D., Director of the Department of Biostatistics and Epidemiology, Department of Biostatistics, School of Health, Social Determinants of Health Research Center, Mashhad University of Medical Sciences, Mashhad, Iran

\section{Type of article: Original}

\begin{abstract}
Background: In order to provide a better healthcare education to the society, health care students should have an acceptable electronic health (E-Health) literacy.

Objective: The aim of this study was to assess the level of E-Health literacy of Medicine and Health Sciences university students in Mashhad, Iran.

Methods: This cross-sectional study was performed on 192 students of Mashhad University of Medical Sciences using a validated Persian translate of the E-Health literacy scale (P-EHEALS) questionnaire in 2016. Demographic data including age, monthly income, level of education, preference of website for obtaining health related information and minutes of Internet use per day were obtained from the subjects. Independent-samples ttest and analysis of variance (ANOVA) were used for comparison between groups, and Pearson correlation coefficient and linear regression were used to assess the correlation between study parameters and EHEALS score using SPSS version 21.

Results: A total of $192(67.2 \%$ female and $32.8 \%$ male $)$ subjects with mean age of $24.71 \pm 5.30$ years participated in the study. Mean P-EHEALS score of the subjects was 28.21 \pm 6.95 . There was a significant difference in PEHEALS score between genders $(p<0.001)$, department $(p=0.001)$, education level $(p<0.001)$ and health status $(\mathrm{p}=0.003)$ as well as monthly income $(\mathrm{p}=0.03)$, website preference categories $(\mathrm{p}=0.02)$. Male students were significantly more likely to gain higher P-EHEALS scores.

Conclusion: The level of E-Health literacy was low in Medical and Health Sciences university students in Mashhad. More studies are needed to assess the contributors to E-Health literacy.

Keywords: e-Health literacy, Iran, University students, Internet, EHEALS
\end{abstract}

\section{Introduction}

The benefits of using the Internet including low cost, high speed in search and the ability to access information anonymously, have made the Internet a preferable choice for searching health information (1). It was previously reported that 8 out of 10 Internet users used internet resources for their health-related questions (2). An important factor that can influence the efficacy of searching for health information as well as type of information sought and the satisfaction of the obtained information, is health literacy (3). Health literacy is defined as "the degree to which

\section{Corresponding author:}

Associate Professor Dr. Nooshin Peyman, Department of Health Education and Health Promotion, School of Health, Social Determinants of Health Research Center, Mashhad University of Medical Sciences, Mashhad, Iran. Tel: +98511-8544643, Fax: +98-511-8517505, Email: peymann@mums.ac.ir

Received: December 03, 2016, Accepted: February 07, 2017, Published: March 2017

iThenticate screening: February 02, 2017, English editing: February 25, 2017, Quality control: March 06,2017

(C) 2017 The Authors. This is an open access article under the terms of the Creative Commons Attribution-NonCommercialNoDerivs License, which permits use and distribution in any medium, provided the original work is properly cited, the use is non-commercial and no modifications or adaptations are made. 
individuals have the capacity to obtain, process, and understand basic health information and services needed to make appropriate health decisions" (4). With the increased usage of the Internet, electronic health literacy (e-Health) has become the center of attention for health care professionals (2). E-health literacy is defined as "the ability to seek, find, understand, and appraise health information from electronic sources, and apply the knowledge gained to addressing or solving a health problem" (5).

Unlike traditional health literacy, which is mainly based on basic literacy skills including the ability to speak and write language as well as to read and understand written passages, e-health literacy encompasses six core skills (traditional literacy, health literacy, information literacy, scientific literacy, media literacy and computer literacy). Therefore e-health literacy is under influence of a variety of factors including age, gender, level of education, availability and accessibility of Internet and income $(6,7)$. Although health literacy is an important issue for the public, health care providers should also learn to use the basic skills to develop and use the electronic sources in order to implement better standards of health services $(8,9)$. In the United States, there is a constant supervision on the content and quality of sources of health information (10). Besides this supervision, the American Medical Association has published guidelines for patients in order to educate them on how they should evaluate and use the Internet for their medical and health inquiries (10). Unlike the United States, such a system does not exist in Iran and therefore there is a high probability that the information spread in the social media be contaminated with myths and rumors instead of evidence based recommendations (11). It has been shown that misinformation may play a negative role in health beliefs and behavior of individuals $(11,12)$. Health care providers, as reliable sources of information, should be aware of the ways to evaluate the sources of information besides basic knowledge of Internet use and EHealth literacy (13). This knowledge will help health care providers address issues and misinformation in the social media as well as workplace and therefore provide a better health education to their target groups (14). This education should start from basic university level (15). Previous studies found that the level of e-Health literacy of undergraduate health students was low and that they felt the need for improving their skills in e-Health literacy (1618). Studies have also shown that university students lack the skills in identifying valuable sources for their information and mainly use low level sources $(14,19)$. Besides, studies have also shown that university students gained the required skills in obtaining information by experience $(14,19)$. It was also shown that even in the North American and European countries, E-Health related education is only provided to students of medical fields, and mainly doctors and specialists and students of other medical related fields are ignored while, there is a lack for such education even in doctoral and specialist level in developing countries (15). Therefore, there is a global attempt to improve the E-Health literacy of students of medicine and medical related fields in order to tackle future global health education issues (15). Based on the previous researches, the Internet penetration rate was reported to be $55 \%$ in Iran and the usage of the Internet in Iran was reported to be $45 \%$ (20). In another study, 98\% of Iranians between the ages of 20 and 30 years were using the Internet (21). This data suggests a high accessibility to the Internet for Iranian youth at post-secondary education level. Regarding the availability of the internet, students need to acquire other skills to benefit from the health information in the Internet. On the other hand, it was shown that Iranian Internet users trusted in the lifestyle modification information provided in unofficial sources including Facebook more than governmental sources (22). Similar to the studies in developed and developing countries, Iranian university students relied on low level websites for obtaining their information needs (23). Regarding the fact that Iranian medicine and healthcare providers deal with a population that trusts more in Internet sources that have higher probability of conducting misinformation, it is crucial for students who study in Medicine and Health Sciences to be aware of the proper use of Internet sources, and to evaluate their validity and credibility despite an effective supervision on the content of Internet sources of health information. Due to the scarcity of data regarding the basic E-Health literacy of Iranian Medicine and Health Science students, this study was conducted to assess the level of EHealth literacy and its required skills and influencing factors on E-Health literacy among Mashhad Medicine and Health Sciences.

\section{Material and Methods}

\subsection{Study design}

This study was a pilot study for assessing the E-Health literacy of Medicine and Health Sciences university students in Mashhad, Iran in order to identify whether the E-Health literacy of Mashhad Medicine and Health Sciences students were adequate for their future career. This cross-sectional study was conducted in the Mashhad University of Medical Sciences. Students from all fields of education in this university were enrolled in the study. This study was approved by the Ethical Committee of the Mashhad University of Medical Sciences. The data collection was performed on September 3rd 2016 and ended on October 4th 2016. Based on the previously published data on EHealth literacy of university students in developing countries and lack of curricular education programs in the field 
of E-Health, it is hypothesized that the E-Health literacy of the Medicine and Health Sciences university students is low. Unfortunately, no cut-off for E-Health literacy scores have been provided and researchers used their own interpretation based on the current and previous observations. Sample size was calculated based on the formula presented by Viechtbauer et al. on sample size for pilot study (24). Using 0.95 as the confidence level and 0.02 as probability (based on the previously reported $2-8 \%$ range of nursing students who reported unconfident in related skills to E-Health literacy, the largest calculated sample size was 149 subjects. Considering $30 \%$ drop out, the final manuscript was 194 subjects (25).

\subsection{Subjects}

The reason for selecting Medicine and Health Sciences university students was due to the fact that these students were going to deal with healthcare seekers who have access to the Internet and may not be aware of the identification of reliable sources, and ask their healthcare providers regarding beneficial sources for their further information requirements. Medicine and Health Sciences graduates should be able to identify, validate and recommend trustworthy sources to their clients in order to improve their health information level and prevent them from receiving rumors and fiction instead of academic material. All volunteered university students who were studying in a field related to Medicine or Health Sciences were eligible to participate in the study. Inclusion criteria were being registered as an Iranian citizen, holding a current student position in the university and willing to participate in the study. Exclusion criteria were physical disability which interfered with Internet and computer use including blindness, paralysis and dyslexia. Subjects were chosen randomly from the list of Students obtained from the university education affairs office. Subjects were approached by the researcher and were informed about the aim and overview of the research. Subjects who were willing to participate in the study signed a written informed consent form.

\subsection{Instruments}

Study subjects were provided with a socio-demographic questionnaire regarding age, department, level of education, household income and their website preference regarding Internet material, whether they prefer to use popular websites that have health information from unknown sources (general websites) or to refer to registered and trusted sources for health information including university and governmental health related websites which specifically provide health care information with scientific and evidence based references (specific sources). Subjects were also required to fill the Persian translate of the e-Health Literacy Scale (P-EHEALS) questionnaire. Similar to the EHealth questionnaire, P-EHEALS questionnaire consists of 8 items, where subjects are required to score each item based on a 5 point Likert-scale ranging from 1 indicating strongly disagree to 5 which indicates strongly agree. Therefore, the P-EHEALS score would range from 8 to 40. The higher P-EHEALS score indicates higher E-Health literacy. EHEALS is a questionnaire which is designed to assess eHealth literacy by measuring skills in finding, analyzing and implementing eHealth to health problems (5). An 8-item short form of this questionnaire was previously generated, and was found to be user friendly (5). This questionnaire, which is able to assess e-Health literacy, has been previously validated in different populations and countries $(5,26-30)$. The validity and reliability of the EHEALS questions were previously reported ranges of $0.92-0.93$ and $0.63-0.93$ respectively $(5,27,29)$. In a study on a separate sample of Mashhad University students, the validity and reliability of the P-EHEALS questionnaire was assessed. The construct validity of the P-EHEALS questionnaire was assessed in an interview with 10 health education experts based on content validity ratio (CVR), and content validity index (CVI) and construct validity were assessed in as study on 164 university students. Exploratory factor analysis revealed two distinct categories in the questions (first 4 vs. second 4 questions). Confirmatory factor analysis revealed acceptable validity for P-EHEALS. The reliability of the P-EHEALS questionnaire was assessed using Cronbach's alpha (overall Cronbach's alpha was 0.89 )

\subsection{Statistical Analysis}

Data was analyzed using IBMC SPSS $\odot$ Statistics version 21 (IBM $\odot$ Corp., Armonk, NY, USA). Continuous variables were checked for normality using the Shapiro-Wilk test. Mean and standard deviation (SD) were used to describe the normally distributed variables while median and interquartile range (IQR) were used to describe nonnormally distributed variables. Categorical variables were described using frequency and percentage. Comparison of the P-EHEALS scores between genders and departments was performed using independent-samples t-test, while the one-way analysis of variance (ANOVA) was used to compare p-EHALS scores between monthly income categories. The Mann-Whitney $U$ test was used for comparison of minutes of Internet use between groups. The Pearson correlation coefficient was used to assess the correlation of age with P-EHEALS score, while the Spearman correlation coefficient was used to assess the correlation between minutes of Internet use and P-EHEAS score. 
Linear regression with backward elimination method was performed to assess the relationship between P-EHEALS score with study parameters. Binary logistic regression analysis was performed with gender as dependent variable and other study variables as dependent variables, in order to identify the e-Health literacy related factors that might be affected by gender. Statistical analyses were considered significant at $\mathrm{p}<0.05$.

\section{Results}

A total of $192(129,67.2 \%$ female and $63,32.8 \%$ male) university students participated in this study. Mean age of the subjects was $24.71 \pm 5.30$ years. Sociodemographic characteristics of subjects are shown in Table 1. Median minutes of Internet use per day was reported as 120.00 , IQR=180.0 minutes (minimum was 10.0 minutes and maximum was 900.0 minutes). The mean P-EHEALS score for the subjects was $28.21 \pm 6.95$. The mean scores for each question of the P-EHEALS are shown in Table 2. There was no significant correlation between total PEHEALS score and age (Pearson correlation coefficient, $\mathrm{r}=0.02, \mathrm{p}=0.83$ ) and minutes of Internet use (Spearman correlation coefficient, $\mathrm{r}=0.07, \mathrm{p}=0.35$ ). There was a significant difference in terms of total P-EHEALS scores between genders $(p<0.001)$, levels of education $(p<0.001)$, departments $(0.001)$ and referral websites $(p=0.02)$ as well as monthly income $(\mathrm{p}=0.03)$ (Table 3$)$. Linear regression analysis revealed a significant relationship between total P-EHEALS score and gender, $\beta=0.27, \mathrm{t}(182)=3.83, \mathrm{p}<0.001$. Logistic regression analysis found that gender was significantly associated with total P-EHEALS score $(\mathrm{p}=0.001, \mathrm{OR}=1.11,95 \% \mathrm{CI}$ for $\mathrm{OR}=1.04,1.17$ ) (Table 4).

Table 1. Sociodemographic characteristics of study subjects

\begin{tabular}{|l|l|l|l|}
\hline Variable & Male & $\mathrm{n}$ & $\%$ \\
\hline \multirow{3}{*}{ Gender } & Female & 63 & 32.0 \\
\hline \multirow{4}{*}{ Monthly income (USD) } & No income & 134 & 68.0 \\
\cline { 2 - 4 } & $<$ US160.00 & 140 & 71.1 \\
\cline { 2 - 4 } & $160-$ USD330 & 20 & 10.2 \\
\cline { 2 - 4 } & $>330.00$ & 12 & 6.1 \\
\hline \multirow{3}{*}{ Level of education } & Graduate & 25 & 12.7 \\
\cline { 2 - 5 } & Post graduate & 99 & 50.3 \\
\hline \multirow{3}{*}{ Department } & Health Sciences & 98 & 49.3 \\
\cline { 2 - 5 } & Medicine & 110 & 55.8 \\
\hline \multirow{3}{*}{ Preferred status } & Healthy & 87 & 44.2 \\
\cline { 2 - 5 } & Illness & 155 & 78.7 \\
\cline { 2 - 5 } & Healthy with illness in family & 28 & 14.6 \\
\hline & General & 60 & 31.3 \\
\cline { 2 - 5 } & Specific & 130 & 67.7 \\
\hline
\end{tabular}

Table 2. Mean score for P-EHEALS questions

\begin{tabular}{|l|l|l|}
\hline Question & Mean & SD \\
\hline Q1: I know how to find helpful health resources on the Internet & 3.42 & 1.10 \\
\hline Q2: I know how to use the Internet to answer my health questions & 3.53 & 1.10 \\
\hline Q3: I know what health resources are available on the Internet & 3.04 & 1.11 \\
\hline Q4: I know where to find helpful health resources on the Internet & 3.17 & 1.09 \\
\hline Q5: I know how to use the health information I find on the Internet to help me & 3.40 & 1.07 \\
\hline Q6: I have the skills I need to evaluate the health resources I find on the Internet & 3.17 & 1.06 \\
\hline Q7: I can tell high quality from low quality health resources on the Internet & 3.00 & 1.09 \\
\hline Q8: I feel confident in using information from the Internet to make health decisions & 3.20 & 1.16 \\
\hline
\end{tabular}


http://www.ephysician.ir

Table 3. Comparison of the total P-EHEALS scores of study subjects between genders, levels of education and departments

\begin{tabular}{|c|c|c|c|c|}
\hline \multicolumn{2}{|l|}{ Variable } & Total P-EHEALS score & $\mathrm{t}$ & p-value \\
\hline \multirow[t]{2}{*}{ Gender } & Female & $24.47 \pm 6.43$ & \multirow[t]{2}{*}{-4.25} & \multirow{2}{*}{$<0.001$} \\
\hline & Male & $28.92 \pm 7.42$ & & \\
\hline \multirow[t]{4}{*}{ Monthly income (USD $\left.{ }^{1}\right)$} & No income & $25.38 \pm 6.90$ & \multirow[t]{4}{*}{3.01} & \multirow[t]{4}{*}{0.03} \\
\hline & $<160.00$ & $29.74 \pm 7.14$ & & \\
\hline & 60-USD330 & $28.50 \pm 6.56$ & & \\
\hline & $>330.00$ & $24.62 \pm 7.26$ & & \\
\hline \multirow[t]{2}{*}{ Department } & Health Sciences & $24.43 \pm 6.54$ & \multirow[t]{2}{*}{-3.40} & \multirow[t]{2}{*}{0.001} \\
\hline & Medicine & $27.84 \pm 7.28$ & & \\
\hline \multirow[t]{2}{*}{ Level of education } & Graduate & $24.03 \pm 6.57$ & \multirow[t]{2}{*}{-3.93} & \multirow[t]{2}{*}{$<0.001$} \\
\hline & Post graduate & $27.90 \pm 7.05$ & & \\
\hline \multirow[t]{2}{*}{ Referral website preference } & General & $24.30 \pm 6.66$ & \multirow[t]{2}{*}{2.35} & \multirow[t]{2}{*}{0.02} \\
\hline & Specific & $26.85 \pm 6.98$ & & \\
\hline \multirow[t]{3}{*}{ Health status } & Healthy & $26.74 \pm 6.75$ & \multirow[t]{3}{*}{6.07} & \multirow[t]{3}{*}{0.003} \\
\hline & Illness & $21.25 \pm 8.07$ & & \\
\hline & Healthy with illness in family & $23.18 \pm 6.95$ & & \\
\hline
\end{tabular}

1: USD=United States Dollar

Table 4. Relation between study parameters and gender

\begin{tabular}{|c|c|c|c|c|c|}
\hline \multirow{2}{*}{ Variable } & \multirow[t]{2}{*}{ Wald } & \multirow[t]{2}{*}{ p-value } & \multirow[t]{2}{*}{ OR } & \multicolumn{2}{|c|}{$95 \% \mathrm{CI}$ for $\mathrm{OR}$} \\
\hline & & & & lower & Upper \\
\hline Age (years) & $<0.001$ & 0.99 & 1.00 & 0.91 & 1.10 \\
\hline Monthly income (USD $\left.{ }^{1}\right)$ & 1.68 & 0.64 & - & - & \\
\hline Department (Medicine) & 1.31 & 0.25 & 2.64 & 0.50 & 13.90 \\
\hline Health status & 5.50 & 0.06 & - & - & - \\
\hline Healthy with illness in family & 1.63 & 0.20 & 0.45 & 0.13 & 1.53 \\
\hline Website preference (Specific) & 0.40 & 0.53 & 1.29 & 0.58 & 2.88 \\
\hline Minutes of Internet use & 1.12 & 0.29 & 1.00 & 0.99 & 1.00 \\
\hline Total P-EHEALS score & 11.93 & $0.001 *$ & 1.11 & 1.04 & 1.17 \\
\hline Level of education (Post gra & 0.21 & 0.65 & 0.67 & 0.12 & 3.74 \\
\hline
\end{tabular}

1: USD = United States Dollar

\section{Discussion}

This study revealed that the mean P-EHEALS score of the subjects was $28.21 \pm 6.95$. In a study on 541 Jordanian nursing students, the mean EHEALS score was 28.96 (31). Although this score was higher than the reported EHEALS score of 24.89 in a previously published study on 88 university students in Hong Kong, China in 2009 (32), the EHEALS score in the current study was lower than the reported EHEAS score of 28.4 from a more recent study on 6th grade school students in China in 2012 (29). This finding implies that e-Health literacy evolves with time, and considering the increasing rate of Internet usage, e-Health literacy should increase rapidly. In contrast, the mean EHEALS score in a sample of a 2,142 Japanese population was 23.4 (33). A reason for the difference in the level of e-Health literacy between Iranian university students and Chinese students might be due to the higher availability of trusted sources of health information in China. Besides the report by the Medical Library Association Consumer and Patient Health Information Section, many American and international websites that are dedicated to providing health and medical information have material in Chinese language, the Chinese government has also made a growing attempt to provide health related information on social media $(34,35)$. Similarly, the lack of an efficient online healthcare system in Japan was identified as a main cause of lower comprehensive health literacy in Japan compared to Europe (33). Although the Internet penetration rate in Iran is slightly higher than China (55\% in Iran vs. $52.3 \%$ in China), higher accessibility of the Internet in Iran may not have been a contributing factor to e-Health literacy but, on the other hand, the lack of the required number of validated and trusted online sources of information in Iran and the reliance of Iranian Internet users on untrusted sources might have attributed to the lower e-Health literacy in Iran compared to China $(22,34,35)$. Furthermore, this study found that ability to identify useful websites and differentiating high quality from low quality sources, accounted for the lowest scores in P-EHEALS. This finding also indicates that university students have good access to the Internet and health related websites, but do not 
have the ability to identify which websites provide trustable information on health issues. This might come from the fact that unlike Europe or the Unites states, the ministry-supported websites that deal with health education are either scarce or less advertised so that they have become difficult to find even by Medicine and Health Sciences students. This study also found a sexual divide in e-Health literacy among Iranian Medical and Health Sciences university students indicating that male students were $27 \%$ more likely to have higher e-Health literacy scores compared to female students. Various reasons have been proposed for the digital divide in societies including ethnicity, poverty and lower level of education (36-38). It was previously shown that lower level of education results in reduced Internet usage, while inequalities in the provision of services, including Internet access to minorities and low income population, was the reason for their reduced Internet access and therefore low e-Health literacy (36-38). On the other hand, previous studies have found either no significant effect for gender on e-Health literacy (31), or a higher attitude and referral to medical websites for women (39, 40). Since no significant association was found between gender and other study parameters, the higher observed scoring in P-EHEALS in men might be due to cultural differences that allow boys and men to have an unlimited access to communication technology from a younger age compared to women. Further research is required to assess the effect of gender in eHealth of university students. One of the strengths of this study was the use of a validated Persian translate of EHEALS questionnaire which provided the opportunity to compare the e-Health literacy of Iranian Medicine and Health Sciences university students with other countries. Furthermore, to the best of our knowledge, this study was the first study that assessed the e-Health literacy in university students in Iran. A weakness of this study might be the small sample size. Due to the design of the study, pilot study, the sample size was calculated and therefore, the results of this study may not be generalized to the total population of Mashhad Medicine and Health Sciences university students. Furthermore, the uneven distribution of duration of Internet usage in the study, prevented the use of more reliable statistical analysis. Therefore, it is recommended that further researchers assess e-Health literacy in a larger sample of the university students who study in Medicine or health Sciences.

\section{Conclusions}

This study found that the level of e-Health literacy is low among the Medicine and Health Sciences university students in Iran and that the female students have a lower e-Health literacy level compared to their male counterparts. It is required for further researchers to assess the level of e-Health literacy in larger samples of university students in order to identify the extent of e-Health literacy in a nationwide assay and make proper decisions to improve the e-Health literacy of students who study in health-related fields. Furthermore, since the aim of this study was not to assess the gender and digital divide in university students, this result was not able to identify the exact reason for lower e-Health literacy in female students. It is recommended that further studies should focus on the contributing factors to e-Health literacy in university students.

\section{Acknowledgments:}

Authors of this study wish to thank all the university authorities who complied with the research and provided support to the researcher as well as the students who participated in the study.

\section{Conflict of Interest:}

There is no conflict of interest to be declared.

\section{Authors' contributions:}

SD and NP designed and performed the study. SD drafted the manuscript. MT participated in the design of the study, HE performed the statistical analysis and interpretation of data. All authors read and approved the final manuscript.

\section{References:}

1) Nasrabadi AN, Sabzevari S, Bonabi TN. Iranian Women's Experiences of Health Information Seeking Barriers: A Qualitative Study in Kerman. Iran Red Crescent Med J. 2015; 17(2): e25156. doi: 10.5812/ircmj.25156. PMID: 25834743, PMCID: PMC4376996.

2) Fox S. The social life of health information, 2011. Pew Internet \& American Life Project Washington, DC; 2011.

3) Sørensen K, Van den Broucke S, Fullam J, Doyle G, Pelikan J, Slonska Z, et al. Health literacy and public health: A systematic review and integration of definitions and models. BMC Public Health. 2012; 12: 80. doi: 10.1186/1471-2458-12-80. PMID: 22276600, PMCID: PMC3292515. 
4) Ratzan SC. Introduction. Selden CR, Zorn M, Ratzan SC, Parker RM In: National Library of Medicine Current Bibliographies in Medicine: Health Literacy. Vol NLM Pub No CBM. 2000; 1.

5) Norman CD, Skinner HA. eHealth Literacy: Essential Skills for Consumer Health in a Networked World. J Med Internet Res. 2006; 8(2): e9. doi: 10.2196/jmir.8.2.e9. PMID: 16867972, PMICD: PMC1550701.

6) Miller EA, West DM. Where's the Revolution? Digital Technology and Health Care in the Internet Age. J Health Polit Policy Law. 2009; 34(2): 261-84. doi: 10.1215/03616878-2008-046. PMID: 19276318.

7) Palsdottir A. Seeking information about health and lifestyle on the Internet. Ir Info Res. 2009; 14(1). doi: 10.1108/00220411011023634.

8) Ball MJ, Lillis J. E-health: transforming the physician/patient relationship. Int J Med Inf. 2001; 61(1): 1-10. doi: 10.1016/S1386-5056(00)00130-1.

9) Institute of Medicine (US) Roundtable on Health Literacy. Health Literacy, eHealth, and Communication: Putting the Consumer First: Workshop Summary. National Academies Press (US); 2009. doi: 10.17226/12474. PMID: 20662120.

10) Hale TM, Goldner M, Stern M, Drentea P, Cotten SR. Patterns of online health searching 2002-2010: Implications for social capital, health disparities and the de-professionalization of medical knowledge. In: Technology, Communication, Disparities and Government Options in Health and Health Care Services. Emerald Group Publishing Limited; 2014. doi: 10.1108/S0275-495920140000032016.

11) Lewandowsky S, Ecker UK, Seifert CM, Schwarz N, Cook J. Misinformation and its correction continued influence and successful debiasing. Psychol Sci Public Interest. 2012; 13(3): 106-31. doi: 10.1177/1529100612451018. PMID: 26173286.

12) Friggeri A, Adamic LA, Eckles D, Cheng J. Rumor Cascades. In: ICWSM. 2014. doi: $10.1057 / 9781137465344.0006$.

13) Metzger MJ, Flanagin AJ. Using Web 2.0 technologies to enhance evidence-based medical information. J Health Commun. 2011; 16 Suppl 1: 45-58. doi: 10.1080/10810730.2011.589881. PMID: 21843095.

14) Stellefson M, Hanik B, Chaney JD, Tennant B. Analysis of eHealth Search Perspectives Among Female College Students in the Health Professions Using Q Methodology. J Med Internet Res. 2012; 14(2): e60. doi: 10.2196/jmir.1969. PMID: 22543437, PMCID: PMC3376519.

15) Liu Y, Zhang Y, Liu Z, Wang J. Gaps in studies of global health education: an empirical literature review. Glob Health Action. 2015; 8(1): 25709. doi: 10.3402/gha.v8.25709. PMID: 25906768, PMCID: PMC4408318.

16) Ivanitskaya L, O Boyle I, Casey AM. Health Information Literacy and Competencies of Information Age Students: Results From the Interactive Online Research Readiness Self-Assessment (RRSA). J Med Internet Res. 2006; 8(2): e6. doi: 10.2196/jmir.8.2.e6. PMID: 16867969, PMCID: PMC1550696.

17) A Competency-Based Framework for Health Educators--2006. Whitehall, PA: United States: National Commission for Health Education Credentia; 2006.

18) Hanik B. E-Health Literacy Competencies among Undergraduate Health Education Students: A Preliminary Study. Int Electron J Health Educ. 2011; 14: 46-58.

19) Civilcharran S, Maharaj MS, Hughes M. Uncovering web search tactics in South African higher education: original research. South Afr J Inf Manag. 2015; 17(1): 1-8. doi: 10.4102/sajim.v17i1.644.

20) Internet World Stats. Internet World Stats. 2012.

21) Alavi SS. The Psychometric Properties of GPIUS, CIUS in Students Internet Users of Isfahan Universities. Final Rep Res Proj Vice Chancellery Res Isfahan Univ Med Sci. 2009; 4(3): 183-9.

22) Eshraghi Y. Evaluation of the internet user's trust to contents of published material in social media (Case study: Facebook and Club). Islamic Azad University Central Tehran Branch, Tehran, Iran. 2016.

23) Asemi A. Information searching habits of Internet users: A case study on the Medical Sciences University of Isfahan, Iran. Webology. 2005; 2(1): 10.

24) Viechtbauer W, Smits L, Kotz D, Budé L, Spigt M, Serroyen J, et al. A simple formula for the calculation of sample size in pilot studies. J Clin Epidemiol. 2015; 68(11): 1375-9. doi: 10.1016/j.jclinepi.2015.04.014. PMID: 26146089.

25) Singh S, Mahapatra RK. Electronic Information Seeking Behaviour Among Nursing Students and Teachers: A Review. Int J Health Sci Res. 2016; 6(9).

26) Tubaishat A, Habiballah L. eHealth literacy among undergraduate nursing students. Nurse Educ Today. 2016; 42: 47-52. doi: 10.1016/j.nedt.2016.04.003. PMID: 27237352.

27) Chan J, Leung A, Chiang VCL, Li HCW, Wong EM, Liu ANC, et al. A pilot project to build e-health literacy among university students in Hong Kong. The Tenth International Congress on Medical Librarianship: Brisbane Australia; 2009. 
28) Koo M, Norman CD, Chang HM. Psychometric Evaluation of a Chinese Version of the eHealth Literacy Scale (eHEALS) in School Age Children. Int Electron J Health Educ. 2012; 15: 29.

29) Nakayama K, Osaka W, Togari T, Ishikawa H, Yonekura Y, Sekido A, et al. Comprehensive health literacy in Japan is lower than in Europe: a validated Japanese-language assessment of health literacy. BMC Public Health. 2015; 15: 505. doi: 10.1186/s12889-015-1835-x. PMID: 26001385, PMCID: PMC4491868.

30) Smith KH. Consumer Health Information Services. Introd Health Sci Librariansh Ed MS Wood. 2014; 32446.

31) Fung ICH, Hao Y, Cai J, Ying Y, Schaible BJ, Yu CM, et al. Chinese Social Media Reaction to Information about 42 Notifiable Infectious Diseases. PLOS ONE. 2015; 10(5): e0126092. doi: 10.1371/journal.pone.0126092. PMID: 25946020, PMCID: PMC4422708.

32) Kontos E, Blake KD, Chou WYS, Prestin A. Predictors of eHealth Usage: Insights on The Digital Divide From the Health Information National Trends Survey 2012. J Med Internet Res. 2014; 16(7): e172. doi: 10.2196/jmir.3117. PMID: 25048379, PMCID: PMC4129114.

33) Kontos EZ, Emmons KM, Puleo E, Viswanath K. Contribution of Communication Inequalities to Disparities in Human Papillomavirus Vaccine Awareness and Knowledge. Am J Public Health. 2012; 102(10): 1911-20. doi: 10.2105/AJPH.2011.300435. PMID: 22970692 , PMCID: PMC3490653.

34) Kontos EZ, Viswanath K. Cancer-related direct-to-consumer advertising: a critical review. Nat Rev Cancer. 2011; 11(2): 142-50. doi: 10.1038/nrc2999. PMID: 21258398.

35) Bidmon S, Terlutter R. Gender Differences in Searching for Health Information on the Internet and the Virtual Patient-Physician Relationship in Germany: Exploratory Results on How Men and Women Differ and Why. J Med Internet Res. 2015; 17(6): e156. doi: 10.2196/jmir.4127. PMID: 26099325, PMCID: PMC4526954.

36) Sarkar U, Karter AJ, Liu JY, Adler NE, Nguyen R, López A, et al. Social disparities in internet patient portal use in diabetes: evidence that the digital divide extends beyond access. J Am Med Inform Assoc. 2011; 18(3): 318-21. doi: 10.1136/jamia.2010.006015. PMID: 21262921, PMCID: PMC3078675. 